\title{
Breast symptoms in adolescents and young adults presenting to a specialist breast clinic
}

Meagan E Brennan, Andrew J Spillane

\begin{abstract}
Background and objective
While breast cancer is rare in adolescents and young adults (AYAs), breast symptoms are common. The aim of this study was to report breast symptoms that prompted referral of AYAs and to examine diagnoses and treatment.
\end{abstract}

\section{Methods}

A retrospective study of AYAs aged $\leq 25$ years who presented in a specialist breast clinic (2007-18) was conducted. Data regarding presentation, diagnosis and management were collected.

\section{Results}

One hundred and thirty-four (128 female, six male) AYAs, with a median age of 21 years, attended the breast clinic in the study period. There was one case of breast cancer (incidence $0.8 \%)$. In females, the most frequent presenting symptoms were 'lump' ( $n=68,53.1 \%)$, 'nipple/areola symptom' ( $n=14,10.9 \%)$ and 'discuss risk of breast cancer' ( $n=10,8.3 \%)$. In males, 'lump' was the most common presenting symptom $(n=5,83 \%)$ and all were cases of gynaecomastia.

\section{Discussion}

A range of breast symptoms are found in AYAs and most can be treated conservatively. Awareness of symptoms and their management will help general practitioners treat young people with breast issues.
BREAST CANCER is rarely diagnosed in people aged $<25$ years, with an age-standardised incidence of 3-5 per million in developed countries. ${ }^{1,2}$

Nevertheless, it is common for adolescents and young adults (AYAs) to present for specialist assessment and advice with breast symptoms that are benign or who have variations of normal development. Reasons for referral include advice about what constitutes 'normal' changes around the time of puberty; the relevance of a family history of breast cancer; and how to investigate breast symptoms in this age group, including the appropriateness of the 'triple test' in these very young people.

The aim of this study was to describe the pattern of breast disease in adolescents and young adults (female and male, aged $\leq 25$ years), including symptoms, diagnosis and management, and to use this information to inform clinicians treating young people.

\section{Methods}

This study was a retrospective audit conducted in a private combined breast physician and breast surgeon clinic in a metropolitan area. The database, which commenced in 2007, was searched in August 2018 to identify AYAs, defined as being aged $\leq 25$ years at the time of their first presentation. Individual records were reviewed, and data on presentation, investigations, diagnosis and management were extracted. Descriptive statistics were used to summarise the data using Microsoft Excel.

Approval was obtained from St Vincent's Human Research Ethics Committee (LNR, SVH File Number 16/114) and the study was conducted in accordance with the National Statement on Ethical Conduct in Human Research 2007 (updated 2015). ${ }^{3}$

\section{Results}

Data are shared online. ${ }^{4}$ One hundred and thirty-four patients aged $\leq 25$ years attended the clinic over an 11-year period (August 2007 to August 2018). Patient characteristics are shown in Table 1 . Most were female $(n=128,95.5 \%)$; six $(4.5 \%)$ were male. The median age was 21.0 years (mean 20.6, range 13-25 years). Eighty-six per cent (109/134) had no significant family history of breast cancer, $47 / 128$ (36.7\%) females were using the oral contraceptive pill and only one patient $(1 / 128,0.8 \%)$ was parous. The median time since the most recent appointment was 17.5 months.

\section{Presenting symptoms}

Presenting symptoms, final diagnosis and management are shown in Tables 2, 3 and 4 . The most frequent presenting symptom was 'lump' in both females 
( $\mathrm{n}=68,53.1 \%$ of presentations) and males ( $\mathrm{n}=5,83 \%$, all cases of gynaecomastia). The second most frequent presenting symptom was 'nipple/areola symptom', in both females $(\mathrm{n}=14,10.9 \%$ of presentations) and males ( $\mathrm{n}=1,16.7 \%)$. In males, there were no other presenting symptoms. In females, the next most frequent concerns were 'discuss risk of breast cancer' ( $n=10,8.3 \%$ ), followed by 'concern about breast appearance', 'inflammation' and 'surveillance of known benign lesion' ( $\mathrm{n}=8,6.3 \%$ each).

The final diagnosis was benign in $133 / 134(99.1 \%)$ cases overall and in $127 / 128$ (99.2\%) females. This included two non-malignant phyllodes tumours (one benign in a female aged 21 years and one borderline in a female aged 14 years). There was one case of cancer that occurred in a woman aged 23 years, without a family history, who presented with a lump. Her lump had suspicious clinical features and malignant features on ultrasound. She had a core biopsy and was diagnosed with a $29 \mathrm{~mm}$, HER2-positive invasive ductal carcinoma and she was treated with neoadjuvant chemotherapy, wide local excision and radiotherapy. She remains well after three years of follow-up.

\section{Breast lumps}

Most female AYAs reporting a lump described a single discrete nodule $(\mathrm{n}=61,89.7 \%)$ rather than a nodular area $(n=7,10.3 \%)$. Solitary (palpable)

\section{Table 1. Characteristics of young people presenting with breast symptoms}

\begin{tabular}{|c|c|c|c|c|}
\hline \multirow[t]{2}{*}{ Characteristic } & \multicolumn{2}{|c|}{ Female $(n=128)$} & \multicolumn{2}{|c|}{ Male $(n=6)$} \\
\hline & $\mathbf{n}$ & $\%$ & $\mathbf{n}$ & $\%$ \\
\hline \multicolumn{5}{|l|}{ Age (years) } \\
\hline $13-15$ & 14 & 10.9 & 0 & 0.0 \\
\hline $16-18$ & 17 & 13.3 & 3 & 50.0 \\
\hline $19-21$ & 42 & 32.8 & 1 & 16.6 \\
\hline $22-24$ & 36 & 28.1 & 1 & 16.6 \\
\hline 25 & 19 & 14.8 & 1 & 16.6 \\
\hline \multicolumn{5}{|c|}{ Risk category (based on family history)* } \\
\hline Average risk & 109 & 85.2 & 6 & 100.0 \\
\hline Moderate risk & 11 & 8.6 & 0 & 0.0 \\
\hline High risk & 8 & 6.3 & 0 & 0.0 \\
\hline \multicolumn{5}{|c|}{ Hormonal contraceptive use (current) ${ }^{\dagger}$} \\
\hline None & 77 & 60.2 & - & - \\
\hline Oral contraceptive & 47 & 36.7 & - & - \\
\hline Other & 3 & 2.4 & - & - \\
\hline Unknown & 1 & 0.8 & - & - \\
\hline
\end{tabular}

\section{Parity ${ }^{+}$}

\begin{tabular}{lrrrrr}
\hline Nulliparous & 127 & 99.2 & - & - \\
\hline Parous & 1 & 0.8 & - & - \\
\hline Total & $\mathbf{1 2 8}$ & $\mathbf{1 0 0 . 0}$ & $\mathbf{6}$ & $\mathbf{1 0 0 . 0}$ \\
\hline
\end{tabular}

${ }^{*}$ Risk category based on Cancer Australia criteria ${ }^{14}$

${ }^{\dagger}$ Female cases only

fibroadenoma was the most common diagnosis in those presenting with 'lump' $(\mathrm{n}=20,29.4 \%)$; half of these were $\leq 20 \mathrm{~mm}$ in size and half were larger. Eight (40\%) were excised (median size $30 \mathrm{~mm}$ ), four (20\%) underwent biopsy and surveillance, and eight (40\%) had surveillance without biopsy. All 14 cases of multiple fibroadenomas had surveillance with or without biopsy (no surgical excision). The two phyllodes tumours were excised; both of these cases proceeded to surgical excision without pre-operative biopsy and the borderline phyllodes underwent re-excision for an involved margin. Overall, the rate of surgery for benign patients presenting with the symptom of 'lump' was 10/67 (14.9\%) and the needle biopsy rate (including cyst aspiration) was $17 / 67$ (25.4\%).

The second most common diagnosis in female AYAs presenting with lumps was 'glandular tissue' $(n=20,29.4 \%$ of 'lump' cases). Other diagnoses in females with lumps were hamartoma $(\mathrm{n}=1)$, sebaceous cyst $(n=1)$, fat lobule $(n=1)$ and cancer $(\mathrm{n}=1)$.

\section{Gynaecomastia}

There were five cases of gynaecomastia in male AYAs, all presenting with the symptom of 'lump'. The ages at presentation were 16, 17, 18, 19, 23 and 25 years. Two cases were bilateral. One patient underwent needle biopsy for diagnosis, the remaining cases were diagnosed using clinical and ultrasound features. Surveillance was the initial recommended treatment in all cases. The patient aged 25 years was prescribed a short-term course of tamoxifen as well as clinical surveillance. Another patient subsequently underwent bilateral subcutaneous mastectomy at age 19 years after diagnosis of gynaecomastia at age 16 years.

\section{Nipple/areolar symptoms}

Nipple/areolar symptoms were the second most common presenting symptom in both female $(14 / 128,10.9 \%)$ and male $(1 / 6$, $16.7 \%)$ AYAs. In females, 6/14 (42.9\%) were normal nipples, $2 / 14$ (14.3\%) were benign inverted nipples and 4/14 (28.6\%) 
were cases of atopic dermatitis (one having a punch biopsy prior to treatment). One woman had a large accessory nipple, which was referred for surgical excision as she was concerned about the cosmetic appearance. The one nipple symptom, 'discharge', in a male was also diagnosed as atopic dermatitis.

\section{Discuss risk of breast cancer}

There were 10 female AYAs $(7.8 \%$ of presentations) who wanted information about their risk of breast cancer and how to manage their risk. Most of these $(n=6$, $60 \%$ ) wanted general advice about the significance of their family history. In addition, there was one female with a

\section{Table 2. Presenting breast symptoms in adolescents and young adults}

\begin{tabular}{|c|c|c|c|c|}
\hline \multirow[t]{2}{*}{ Presenting symptom } & \multicolumn{2}{|c|}{ Female ( $n=128)$} & \multicolumn{2}{|c|}{ Male $(n=6)$} \\
\hline & $\mathbf{n}$ & $\%$ & $\mathbf{n}$ & $\%$ \\
\hline Lump & 68 & 53.1 & 5 & 83.0 \\
\hline Lump & 61 & 89.7 & 5 & 100.0 \\
\hline Nodular area & 7 & 10.3 & - & - \\
\hline Nipple/areolar symptom & 14 & 10.9 & 1 & 16.7 \\
\hline Skin change & 4 & 28.6 & 1 & 100.0 \\
\hline Inverted nipple & 2 & 14.3 & - & - \\
\hline Lump & 2 & 14.3 & - & - \\
\hline Nipple discharge & 6 & 42.9 & - & - \\
\hline Discuss risk of breast cancer & 10 & 7.8 & - & - \\
\hline Screening advice based on $\mathrm{FH}$ & 6 & 60.0 & - & - \\
\hline$B R C A$ mutation carrier & 1 & 10.0 & - & - \\
\hline Discuss FH pre-augmentation & 1 & 10.0 & - & - \\
\hline Discuss $\mathrm{FH}$ before starting OCP & 1 & 10.0 & - & - \\
\hline Discuss history of mantle radiation & 1 & 10.0 & - & - \\
\hline Concern about breast appearance & 10 & 7.8 & - & - \\
\hline Asymmetry & 5 & 50.0 & - & - \\
\hline Shape & 3 & 30.0 & - & - \\
\hline Macromastia & 2 & 20.0 & - & - \\
\hline Inflammation & 8 & 6.3 & - & - \\
\hline Acute inflammation & 4 & 50.0 & - & - \\
\hline Recent inflammation, resolved & 4 & 50.0 & - & - \\
\hline Surveillance of known benign lesion & 8 & 6.3 & - & - \\
\hline Multiple fibroadenomas & 8 & 100.0 & - & - \\
\hline Mastalgia & 6 & 4.7 & - & - \\
\hline Mastalgia & 3 & 50.0 & - & - \\
\hline Mastalgia and nodularity & 3 & 50.0 & - & - \\
\hline Incidental ultrasound finding & 4 & 3.1 & - & - \\
\hline Benign lesion for management & 4 & 100.0 & - & - \\
\hline Total & 128 & 100.0 & 6 & 100.0 \\
\hline
\end{tabular}

FH, family history; OCP, oral contraceptive pill

confirmed BRCA2 gene mutation, one with a past history of mantle radiotherapy, and two females wanting information about screening issues prior to commencing the contraceptive pill $(\mathrm{n}=1)$ or undergoing breast augmentation surgery $(n=1)$. After assessment, there were $4 / 10$ cases $(40 \%)$ considered to be at average or moderate risk of cancer and $6 / 10(60 \%)$ at high risk because of family history, BRCA mutation or previous radiation. Eight (80\%) were advised that no screening was needed at their current age, and two were advised to commence screening at the present time.

\section{Concern about breast appearance}

Ten female AYAs (7.8\% of presentations) expressed concern about their breast appearance. Half were teenagers (aged 13 [two cases], 14, 15 and 19 years) and the others were aged between 20 and 25 years. Three cases (aged 20 [two cases] and 25 years) subsequently proceeded with bilateral breast reduction surgery for symmetrical macromastia. Two of the 10 underwent surgical procedures to correct asymmetry after a period of observation; one had a size discrepancy greater than two cup sizes and had the larger breast reduced (after initially presenting at age 15 years), and the other underwent a bilateral reduction/mastopexy procedure to correct minor asymmetry after presenting at age 21 years. The remaining 5/10 (50\%) female AYAs chose no further intervention after being reassured that there was no breast pathology found at assessment (one with normal symmetrical breasts, one with symmetrical tuberous breast shape, and three with normal but asymmetrical breasts).

\section{Inflammatory symptoms}

Eight female AYAs (6.3\% of presentations) had inflammatory symptoms; none were lactating. Four had breast abscess, two of these requiring aspirations. The remaining four inflammatory cases were caused by inflamed cyst $(\mathrm{n}=2)$, mastitis $(\mathrm{n}=1)$ and infected sebaceous cyst $(n=1)$. All inflammatory cases were treated with oral antibiotics. 


\section{Other symptoms}

Other reasons for consultation were surveillance of multiple fibroadenomas $(\mathrm{n}=8,6.3 \%)$, three requiring biopsy; mastalgia $(n=6,4.7 \%)$; and management of an incidental ultrasound-detected lesion $(\mathrm{n}=4,3.1 \%)$. All were recommended for surveillance rather than biopsy.

\section{Discussion}

The incidence of cancer in females in this cohort was low $(1 / 128,0.8 \%)$, but still much higher than the population incidence would predict. It is also higher than a reported cohort of over 10,000 patients presenting to a breast clinic in the UK, in which no malignancies were seen. ${ }^{2}$ However, there is only one case of cancer in a relatively small cohort, so firm conclusions cannot be drawn. Cancer is often difficult to diagnose in young women because of a low level of suspicion on the basis of age and the challenge of detecting cancer in young women who have dense breast tissue. In this study, the one case of cancer presented with a lump and had suspicious features on ultrasound, resulting in prompt biopsy and diagnosis without evidence of the diagnostic challenges that may occur in a patient aged 25 years.

Breast symptoms in male AYAs were infrequent in this study, accounting for only $6 / 134(4.5 \%)$ presentations. Gynaecomastia was diagnosed in $83 \%$ of these cases. This was not unexpected as gynaecomastia is the most common breast symptom in adolescent males, occurring in up to $48 \%$ of young men around the time of puberty. ${ }^{5}$

The distribution of benign breast disease in females reported in this study is similar to previous studies in the UK and Australia. ${ }^{2,6}$ In those studies, lumps, pain, nipple changes and breast asymmetry were the most common symptoms. ${ }^{2,6}$ In addition, inflammatory symptoms/ abscess (likely related to cysts that develop spontaneous infection) in the years around puberty were reported in those studies, similar to the findings in this study. ${ }^{2,6}$

In the present study, biopsy or aspiration was performed in 17/58 (29.3\%) of young women presenting with

\section{Table 3. Final diagnosis according to presenting symptom}

\begin{tabular}{|c|c|c|c|c|}
\hline \multirow[t]{2}{*}{ Presenting symptom and diagnosis } & \multicolumn{2}{|c|}{ Female $(n=128)$} & \multicolumn{2}{|c|}{ Male $(n=6)$} \\
\hline & $\mathrm{n}$ & $\%$ & $\mathrm{n}$ & $\%$ \\
\hline Lump & 68 & 53.1 & 5 & 83.0 \\
\hline Fibroadenoma (solitary palpable) & 20 & 29.4 & - & - \\
\hline$\leq 20 \mathrm{~mm}$ & 10 & 50.0 & - & - \\
\hline $21-30 \mathrm{~mm}$ & 6 & 30.0 & - & - \\
\hline $31-40 \mathrm{~mm}$ & 2 & 10.0 & - & - \\
\hline $41-50 \mathrm{~mm}$ & 1 & 5.0 & - & - \\
\hline$>50 \mathrm{~mm}$ & 1 & 5.0 & - & - \\
\hline Glandular tissue & 20 & 29.4 & - & - \\
\hline Fibroadenoma (multiple) & 14 & 20.6 & - & - \\
\hline Cyst (simple) & 8 & 11.8 & - & - \\
\hline Phyllodes tumour & 2 & 3.0 & - & - \\
\hline Benign $(40 \mathrm{~mm})$ & 1 & 50.0 & - & - \\
\hline Borderline $(28 \mathrm{~mm})$ & 1 & 50.0 & - & - \\
\hline Invasive ductal carcinoma & 1 & 1.5 & - & - \\
\hline Hamartoma & 1 & 1.5 & - & - \\
\hline Fat lobule & 1 & 1.5 & - & - \\
\hline Sebaceous cyst & 1 & 1.5 & - & - \\
\hline Gynaecomastia & - & - & 5 & 100.0 \\
\hline Unilateral & - & - & 3 & 60.0 \\
\hline Bilateral & - & - & 2 & 40.0 \\
\hline Nipple/areolar symptom & 14 & 10.9 & 1 & 16.7 \\
\hline Normal nipple & 6 & 42.9 & - & - \\
\hline Atopic dermatitis & 4 & 28.6 & 1 & 100.0 \\
\hline Benign nipple inversion & 2 & 14.3 & - & - \\
\hline Accessory nipple & 1 & 7.1 & - & - \\
\hline Montgomery's tubercle & 1 & 7.1 & - & - \\
\hline Discuss risk of breast cancer & 10 & 7.8 & & \\
\hline $\mathrm{FH}$, high risk category & 4 & 40.0 & - & - \\
\hline $\mathrm{FH}$, moderate risk category & 3 & 30.0 & - & - \\
\hline $\mathrm{FH}$, average risk category & 1 & 10.0 & - & - \\
\hline Previous mantle radiation, high risk & 1 & 10.0 & - & - \\
\hline$B R C A$ mutation carrier & 1 & 10.0 & - & - \\
\hline Concern about breast appearance & 10 & 7.8 & & \\
\hline Normal & 3 & 30.0 & - & - \\
\hline Asymmetry $\geq 2$ cup sizes & 3 & 30.0 & - & - \\
\hline Macromastia & 3 & 30.0 & - & - \\
\hline Tuberous breasts & 1 & 10.0 & - & - \\
\hline Inflammation & 8 & 6.3 & & \\
\hline Abscess, non-lactational & 4 & 50.0 & - & - \\
\hline Infected sebaceous cyst & 1 & 12.5 & - & - \\
\hline Inflamed cyst & 2 & 25.0 & - & - \\
\hline Mastitis, non-lactational & 1 & 12.5 & - & - \\
\hline Surveillance of known benign lesion & 8 & 6.3 & & \\
\hline Multiple fibroadenomas & 8 & 100.0 & - & - \\
\hline Mastalgia & 6 & 4.7 & & \\
\hline Glandular tissue & 6 & 100.0 & - & - \\
\hline Incidental ultrasound finding & 4 & 3.9 & & \\
\hline Benign cystic or solid lesion & 4 & 100.0 & - & - \\
\hline Total & 128 & 100.0 & 6 & 100.0 \\
\hline
\end{tabular}


'lump'. Guidelines for breast diagnosis recommend the use of the 'triple test' (clinical breast examination, imaging and percutaneous biopsy) when women present with a new palpable lump. ${ }^{7,8}$ In the general population, the triple test has a sensitivity of $99.6 \%$, mammography alone has a sensitivity of $90 \%$ and approximately $3 \%$ of cancers would be missed if biopsy were omitted. ${ }^{9}$ In very young women, however, triple testing is not essential in all cases and biopsy can safely be omitted where clinical and ultrasound features are completely benign

\begin{tabular}{|c|c|c|c|c|}
\hline \multirow[t]{2}{*}{ Presenting symptom and management } & \multicolumn{2}{|c|}{ Female $(n=128)$} & \multicolumn{2}{|c|}{ Male $(n=6)$} \\
\hline & $\mathbf{n}$ & $\%$ & $\mathbf{n}$ & $\%$ \\
\hline Lump & 68 & 53.1 & 5 & 83.0 \\
\hline Surveillance & 39 & 57.4 & 2 & 40.0 \\
\hline Biopsy and surveillance & 15 & 22.1 & 1 & 20.0 \\
\hline Surgical excision, benign lump in female & 10 & 14.7 & - & - \\
\hline Aspiration & 2 & 2.9 & - & - \\
\hline Cancer management & 1 & 1.5 & - & - \\
\hline Reassurance and discharge & 1 & 1.5 & - & - \\
\hline Tamoxifen, male gynaecomastia & - & - & 1 & 20.0 \\
\hline Surgical excision, male gynaecomastia & - & - & 1 & 20.0 \\
\hline Nipple/areolar symptom & 14 & 10.9 & 1 & 16.7 \\
\hline Reassurance & 9 & 64.3 & - & - \\
\hline Dermatitis treatment & 3 & 21.4 & 1 & 100.0 \\
\hline Punch biopsy, dermatitis treatment & 1 & 7.1 & - & - \\
\hline Surgery & 1 & 7.1 & - & - \\
\hline Discuss risk of breast cancer & 10 & 7.8 & & \\
\hline Screening advice (for future screening) & 8 & 80.0 & - & - \\
\hline Screening advice (to commence now) & 2 & 20.0 & - & - \\
\hline Concern about breast appearance & 10 & 7.8 & & \\
\hline Reassurance & 5 & 50.0 & - & - \\
\hline Referral for surgery & 5 & 50.0 & - & - \\
\hline Inflammation & 8 & 6.3 & & \\
\hline Antibiotics & 6 & 75.0 & - & - \\
\hline Antibiotics and aspiration & 2 & 25.0 & - & - \\
\hline Surveillance of known benign lesion & 8 & 6.3 & & \\
\hline Surveillance & 5 & 37.5 & - & - \\
\hline Biopsy and surveillance & 3 & 62.5 & - & - \\
\hline Mastalgia & 6 & 4.7 & & \\
\hline Symptomatic treatment & 6 & 100.0 & - & - \\
\hline Incidental ultrasound finding & 4 & 3.1 & & \\
\hline Surveillance & 4 & 100.0 & - & - \\
\hline Total & 128 & 100.0 & 6 & 100.0 \\
\hline
\end{tabular}

and lesions are followed up. ${ }^{2,10}$ This is supported by the present study, where $70 \%$ of 'lump' cases did not have needle biopsy to complete the triple test yet no additional cases of cancer were seen after a median follow-up of 17.5 months.

The presence of symptomatic benign breast disease in young women may be a predictor of future breast disease. A diagnosis of a benign proliferative breast condition, particularly when associated with atypia, was established as a risk factor for breast cancer many years ago. ${ }^{11}$ The association is stronger when the atypia is diagnosed at a younger age and when a family history of breast cancer is present. ${ }^{11}$ The cohort reported in this study did not have any benign biopsies that showed proliferative change or atypia; however, it has been hypothesised that for some young women a diagnosis of benign breast disease at a very young age will be associated with benign breast disease in adulthood, and (if atypia is found) there may also be an increased risk of future cancer. ${ }^{12}$

Population studies have examined non-breast factors at adolescence and their association with benign breast disease in adulthood. ${ }^{12,13}$ Benign breast disease in adults is associated with low body mass index in adolescence, higher growth velocity, and high intake of red meat and alcohol; late menarche was not protective against adult breast disease. ${ }^{13}$ It may therefore be prudent to follow up young women with benign breast disease as they grow up, take the opportunity to educate them about breast care and discuss the importance of lifestyle factors from this very young age. As modifiable risk factors play a significant part in breast cancer risk, adolescents should not be considered too young to discuss lifestyle issues and primary prevention of breast cancer. ${ }^{12}$ This is particularly the case in girls who present to discuss their risk of breast cancer as it relates to their family history ( $7.8 \%$ of this cohort), as they may be especially receptive to this information.

This study's main limitation is its small sample size. Its strength is the detailed information available about presentation, investigation and management. 


\section{Conclusions}

A large range of benign breast symptoms can present in AYAs. Most can be managed conservatively. When clinical breast examination and ultrasound show benign features, biopsy can often be omitted, and surgery is usually not indicated. The future implications of benign breast disease in adolescence is unknown; however, the opportunity can be used to promote breast health and awareness of lifestyle factors that affect breast cancer risk.

\section{Implications for general practice}

- Breast symptoms in adolescents are common and are unlikely to be cancer.

- In females, fibroadenoma, cyst, phyllodes tumour, nipple symptom, abscess and breast asymmetry are the most common reasons for presentation.

- In males, gynaecomastia is the most common diagnosis.

- Most breast conditions in young people can be managed conservatively.

- Where features on clinical breast examination and ultrasound are benign, biopsy is not always required.

- Surgery is usually not indicated in AYAs with breast symptoms.

\section{Authors}

Meagan E Brennan FRACGP, FASBP, PhD, Clinica Associate Professor, Breast Physician, Northern and Westmead Clinical Schools, School of Medicine, Faculty of Medicine and Health, University of Sydney, NSW. Meagan.brennan@sydney.edu.au

Andrew J Spillane MD, FRACS, Professor of Surgical Oncology, Northern Clinical School, School of Medicine, Faculty of Medicine and Health, University of Sydney, NSW; Surgical Oncologist, Royal North Shore and Mater Hospitals, North Sydney, NSW Competing interests: None.

Funding: None.

Provenance and peer review: Not commissioned, externally peer reviewed.

\section{References}

1. Australian Institute of Health and Welfare. Cancer in adolescents and young adults in Australia. Cat. no. CAN 110. Canberra: AIHW, 2018.

2. Yue D, Swinson C, Ravichandran D. Triple assessment is not necessary in most young women referred with breast symptoms. Ann R Coll Surg Engl 2015;97(6):466-68. doi: 10.1308/ rcsann.2015.0019.

3. National Health and Medical Research Council: Australian Research Council; Australian ViceChancellors' Committee. National statement on ethical conduct in human research 2007 (updated May 2015). Canberra: NHMRC, 2015.

4. Brennan ME, Spillane AJ. Breast disease in adolescent females and males 2018. Mendeley Data, V1. doi: 10.17632/mk4c23vtcx.1.

5. Biro FM, Lucky AW, Huster GA, Morrison JA. Hormonal studies and physical maturation in adolescent gynecomastia. J Pediatr 1990;116(3):450-55.

6. Foxcroft LM, Evans EB, Hirst C, Hicks BJ. Presentation and diagnosis of adolescent breast disease. Breast 2001;10(5):399-404. doi: 10.1054/ brst.2001.0292.
7. Cancer Australia. Investigation of a new breast symptom: A guide for general practitioners. Surry Hills, NSW: Cancer Australia, 2017.

8. Willett AM, Loftus R, Lee MJR, Hughes J; CRS Breast Cancer Working Group. Best practice diagnostic guidelines for patients presenting with breast symptoms. Canberra: National Cancer Action Team, 2010

9. Irwig L, Macaskill P, Houssami N. Evidence relevant to the investigation of breast symptoms: The triple test. Breast 2002;11(3):215-20. doi: 10.1054/brst.2001.0409.

10. O'Neill AC, Shine S, Coffey L, Pender S, O'Doherty A, McNally S. Audit on breast ultrasound in women under 25 years. Ir J Med Sci 2013;182(2):287-89. doi: 10.1007/s11845-0120877-7.

11. Dupont WD, Page DL. Risk factors for breast cancer in women with proliferative breast disease. N Engl J Med 1985;312(3):146-51. doi: 10.1056/ NEJM198501173120303.

12. Frazier $A L$, Rosenberg SM. Preadolescent and adolescent risk factors for benign breast disease. J Adolesc Health 2013;52(5 Suppl):S36-40. doi: 10.1016/j.jadohealth.2013.01.007.

13. Berkey CS, Willett WC, Frazier AL, Rosner B, Tamimi RM, Colditz GA. Prospective study of growth and development in older girls and risk of benign breast disease in young women. Cancer 2011;117(8):1612-20. doi: 10.1002/cncr.25692.

14. Cancer Australia. Family history assessment FRA-BOC introduction. Surry Hills, NSW: Cancer Australia, 2011. Available at https:// canceraustralia.gov.au/clinical-best-practice/ gynaecological-cancers/fra-boc/evaluate [Accessed 25 January 2019].

correspondence ajgp@racgp.org.au 